Pure Appl. Chem., Vol. 82, No. 2, pp. 409-427, 2010.

doi:10.1351/PAC-CON-09-06-08

(C) 2010 IUPAC, Publication date (Web): 25 January 2010

\title{
Biotransformation of metal(loid)s by intestinal microorganisms*
}

\author{
Roland A. Diaz-Bone ${ }^{1, \ddagger}$ and Tom Van de Wiele ${ }^{2}$ \\ ${ }^{1}$ Microbiology I and Institute of Environmental Analytical Chemistry, University of \\ Duisburg-Essen, Essen, Germany; ${ }^{2}$ Laboratory of Microbial Ecology and \\ Technology, University of Gent, Gent, Belgium
}

\begin{abstract}
Many metals and metalloids undergo complex biotransformation processes by microorganisms in the environment, namely, Ge, As, Se, Cd, In, Sn, Sb, Te, Hg, Tl, Pb, Bi, and Po. Though the human intestine harbors a highly diverse and metabolically active microbial community, the knowledge on metal(loid) biotransformation by gut microbiota is limited. Microbial metal(loid) metabolism in the gut is highly relevant when assessing health risks from oral exposure, as both the bioavailability and the toxicity of the ingested compound can be modulated. This review gathers and compares a broad selection of scientific studies on the intestinal biotransformation of metal(loid)s.

It can be inferred that metal(loid) biotransformation by intestinal microbiota is a common process, resulting in both beneficial and adverse toxicological effects. Whereas for $\mathrm{Hg}$ the intestinal demethylation of methylmercury results in enhanced elimination, highly bioavailable and toxic arsenic and Bi species are formed by intestinal microorganisms. In either case, we conclude that the gut microbial potency should be considered to be taken up in toxicokinetic studies and models for assessing the health risks of oral metal(loid) exposure. This will allow the relevance of intestinal metal(loid) biotransformation to be assessed for human health risks.
\end{abstract}

Keywords: colon microflora; biomethylation; metals; metalloids; risk assessment; speciation; thiolation; volatilization.

\section{INTRODUCTION}

Biotransformation of metals and metalloids is a widespread and important process in the environment. A wide range of different metal(loid) biotransformation processes has been reported, including reduction and oxidation, methylation and demethylation, hydrogenation, the addition of $\mathrm{S}$ (thiolation) as well as incorporation of the metal(loid) into more complex metal(loid) organic compounds such as arsenosugars, for example. Due to the change of mobility, bioavailability, and toxicity, these processes play a major role in the biogeochemical cycles of many metal(loid)s such as, e.g., $\mathrm{Hg}$, As, Se, and Ge [1].

In the environment, microorganisms are the most important actors in biotransforming metal(loid)s, both quantitatively and qualitatively when considering the spectrum of elements metabolized. Microorganisms have been shown to be capable of methylating a wide range of metals including Ge, Cd, In, Sn, Hg, Tl, Pb, Bi, and Po as well as metalloids, including As, Se, Sb, and Te [2]. Of these

\footnotetext{
*Paper based on a presentation at the $3^{\text {rd }}$ International Symposium on Trace Elements in Food (TEF-3), 1-3 April 2009, Rome, Italy. Other presentations are published in this issue, pp. 349-481.

¥Corresponding author
} 
elements, the only two, for which enzymatic methylation has been shown in the human body are As and Se [3]. Furthermore, indications for endogenous methylation of Bi and Te exist (see below). In addition to the broader element spectrum, microorganisms are in general able to catalyze more versatile biotransformation reactions and thereby produce a more diverse species spectrum.

When assessing the human health risks from an ingested metal(loid), two aspects should be covered: (1) the bioavailable fraction — or internal exposure - of the metal(loid) or one of its metabolites and (2) the biological activity of these substances in the human body. To address these issues, many in vitro methods mimicking the upper gastrointestinal tract can be or have been combined with pharmacokinetic models [4-6]. This allows one to monitor the release of a metal(loid) from its matrix during gastrointestinal transit, intestinal absorption through the gut epithelium, biotransformation by enterocytes or hepatocytes and eventually, distribution, accumulation inside or excretion from the body.

In terms of bioavailability research, current risk assessment practices only consider the digestive processes taking place in the stomach and small intestine and the absorption across the intestinal epithelium. In terms of biological activity, it is primarily human metabolism that has been highlighted. Yet, the vast microbial community from the colon is capable of modulating both the release of substances out of a matrix as well as the chemical speciation of the released substance. In spite of the knowledge of the importance of microbial biotransformation of metal(loid)s, it is therefore remarkable that the metabolic potency from intestinal microorganisms toward metal(loid)s has not been well addressed. Moreover, it is not known to what extent metal(loid) biotransformation by intestinal microorganisms contributes to the total health risks upon oral exposure of metal(loid)s.

The human large intestine harbors an incredibly diverse microbial ecosystem comprising more than 1000 species at concentrations of $10^{12}$ microorganisms per gram gut content, the highest recorded for any microbial habitat [7]. The total number of microbial genes (known as the metagenome) in these communities (the microbiome) ranges from 2 to 4 million, which is $70-140$ times more than that of their host. Comparing small and large intestine, both the cell numbers $\left(10^{6} \mathrm{vs} .10^{11} / \mathrm{ml}\right)$ and the residence time (3-6 h vs. 24-72 h) are lower in the small intestine, therefore, the colon is the primary site for microbial metabolism of ingested substances. It has been shown that the gut microbial community has the ability to metabolize xenobiotics far more extensively than any other part in the body (reviewed by Sousa et al. [8]). In fact, the amount of catabolic reactions and biotransformation processes from gut microbial origin is at least or may even outnumber the amount of metabolic processes from the liver [9]. This microbial factor in the metabolism of ingested chemicals has often been overlooked, yet the last decade of scientific research has brought new insights and surprising findings. Indeed, since many compounds in the large intestine can be transported across the epithelium, the action of colon microbiota obviously has consequences when assessing the risks from, e.g., ingested hydrocarbon contaminants. Mikov nicely summarizes the importance of gut microbiota, stating that the gut microbial metabolism must be considered an integral part of drug/xenobiotic metabolism and toxicity studies [10]. The health modulation by gut microbiota should not be underestimated. In 1993, an accident with an antiviral drug, orivudine, resulted in the dramatic death of 18 patients [11]. The gut microbial metabolite (E)-5-(2-bromovinyl)uracil had interfered with the clearance of a co-administered anti-cancer drug 5-fluorouracil and caused fatality in many patients. Such events illustrate the necessity to study metal(loid) speciation changes by gut microbiota more in-depth.

In this review, we provide a concise overview of the studies investigating the intestinal biotransformation of those metal(loid)s, which undergo biomethylation in the environment. We will particularly focus on finding evidence for two fundamental questions: (i) Are microorganisms from the human gut capable of metabolizing metal(loid)s? and (ii) Can gut microbes thereby modulate bioavailability and hence toxicity of ingested metal(loid)s? Furthermore, we will compare the different experimental approaches for studying intestinal biotransformation and discuss the challenges that lie ahead when elucidating the intestinal biotransformation of metal(loid)s. 


\section{INTESTINAL BIOTRANSFORMATION OF As}

\section{Reduction, methylation, and demethylation of As compounds by intestinal microorganisms}

The first study investigating the bioderivatization of metal(loid)s by intestinal microorganisms dates back to 1917. Puntoni isolated several microbial strains from fecal samples of patients undergoing treatment with dimethylarsinic acid $\left[\left(\mathrm{CH}_{3}\right)_{2} \mathrm{AsO}(\mathrm{OH}), \mathrm{DMAs}^{\mathrm{V}}\right]$ by using a culture medium amended with $2 \% \mathrm{DMAs}^{\mathrm{V}}$ [12]. Three microbial isolates, namely, Bacillus subtilis, B. medenterious vulgatus, and B. medenterious ruber produced a characteristic garlic odor, presumably indicating trimethylarsine $\left[\left(\mathrm{CH}_{3}\right)_{3} \mathrm{As}\right.$, TMAs], upon amendment with either DMAs ${ }^{\mathrm{V}}$ or arsenate. The intensity of the odor was more intense upon amending $\mathrm{DMAs}^{\mathrm{V}}$ than amending arsenate. As Puntoni's results were the first showing As volatilization by bacteria, Challenger and Higginbottom tried to reproduce these results in 1935 [13]. They did not succeed in reproducing the volatilization, probably because of the use of pure bacterial cultures from a microbial strain database.

Rowland and Davies investigated the biotransformation of radiolabeled sodium arsenate [iAs ${ }^{\mathrm{V}}$ ] by stomach, small intestine, and cecal contents of rats in vitro [14]. Within $48 \mathrm{~h}$, approximately $50 \%$ was reduced to arsenite [iAs ${ }^{\mathrm{III}}$ ] and some 20-30\% were methylated to monomethylarsonous acid $\left[\mathrm{CH}_{3} \mathrm{AsO}(\mathrm{OH})_{2}, \mathrm{MMAs}^{\mathrm{V}}\right]$ and $\mathrm{DMAs}^{\mathrm{V}}$ in the presence of cecal contents. The importance of microbial activity for As metabolism was demonstrated by autoclaving, $0.45 \mu \mathrm{m}$ filtration, antibiotic inhibition, and the use of cecal contents from germ-free mice. In all cases, both reduction and methylation were negligible.

Cullen et al. administered radiolabeled methyl arsine oxide $\left[\left(\mathrm{CH}_{3} \mathrm{AsO}\right)_{x}, \mathrm{MMAs}{ }^{\mathrm{III}}\right]$ either to ceca from untreated mice or orally to four mice [15]. After $4 \mathrm{~h}$ of incubation, the As speciation was analyzed by both liquid and thin-layer chromatography. In both experiments, $\mathrm{iAs}^{\mathrm{V}}$ and DMAs ${ }^{\mathrm{V}}$ were detected.

The mechanism of As methylation was studied more in detail by Hall et al., who investigated the capability of mice cecal microbiota to methylate arsenic in vitro. They found transformation of up to $50 \%$ of both As and arsenate to MMAs ${ }^{\mathrm{V}}$ and DMAs ${ }^{\mathrm{V}}$ within $21 \mathrm{~h} \mathrm{[16].} \mathrm{In} \mathrm{the} \mathrm{concentration} \mathrm{range} \mathrm{from}$ 0.1 to $10 \mu \mathrm{M}$ arsenite or arsenate, a linear increase of methylated species was observed, whereas at the $100 \mu \mathrm{M}$ level an inhibition or saturation was observed. Methylation was increased by addition of methyl group donors $S$-adenosyl-L-methionine (SAM) and methylcobalamin as well as glutathione. Similar to the results from Rowland and Davies, selenite inhibited methylation. In both studies, speciation was performed by thin-layer chromatography using radiolabeled As standards. Hence, no structural information was obtained in particular concerning the incorporation of thiol groups (see below).

The reduction of As by gut bacteria has been studied in detail by Herbel et al. using slurried fecal samples from hamsters given drinking water with either no As or $100 \mathrm{mg}$ iAs $\mathrm{V} / 1$ [17]. Approximately 70 or $45 \%$ of iAs ${ }^{\mathrm{V}}$ were reduced to iAs ${ }^{\mathrm{III}}$ within $48 \mathrm{~h}$ by fecal samples from As-exposed and non-exposed hamsters, respectively. In addition to As reduction as resistance mechanisms, Herbel et al. proposed dissimilatory As reduction (DAsR) as the responsible process. Indeed, arsenate reduction was strongly inhibited by aerobic conditions and tungstate, which is an inhibitor for the Mo-containing cofactor of DAsR, and thereby inhibits arsenate reduction. Furthermore, they were able to isolate a strain capable of DAsR, which was identified as a low $\mathrm{G}+\mathrm{C}$ Gram-positive Bacillus species.

Conversion of arsenobetaine $\left[\left(\mathrm{CH}_{3}\right)_{3} \mathrm{AsCH}_{2} \mathrm{COOH}\right.$, AsBet] by intestinal bacteria has been shown, but only under aerobic conditions. Intestinal bacteria of a mollusk transformed AsBet to TMAsO and DMAs ${ }^{\mathrm{V}}$ [18], microbiota of the freshwater crayfish Procambarus clarkii to TMAsO, $\mathrm{DMAs}^{\mathrm{V}}, \mathrm{MMAs}^{\mathrm{V}}$, and a non-identified metabolite [19]. Human intestinal microorganisms metabolized AsBet to DMAsV , TMAsO as well as dimethylarsinoylacetate [20]. 


\section{Thiolation of As compounds by intestinal microorganisms}

Whereas methylation was originally considered a detoxification process due to the low toxicity of pentavalent oxoforms of mono- and dimethyl As, the role of highly toxic trivalent methylarsenicals and in particular the thiolated methylarsenic species is currently under intensive debate [21]. A number of different studies indicate that, in particular, thiolated As species can be extensively formed in the human intestine due to the highly reducing conditions and the high $\mathrm{S}$ concentrations.

In a series of consecutive publications, a group from the Department of Preventive Medicine and Environmental Health from the Osaka City University Medical School investigated the in vivo metabolism of DMAs ${ }^{\mathrm{V}}$ in rats chronically exposed via drinking water by use of ion chromatography hyphenated to inductively coupled plasma mass spectrometry (IC-ICP-MS). In their first study raising the hypothesis of intestinal microbial involvement in As metabolism, DMAs ${ }^{\mathrm{V}}$ orally administered to rats in different concentrations $(2,10,25,50$, and $100 \mathrm{mg} / \mathrm{l})$ was metabolized to TMAsO and iAs ${ }^{\mathrm{III}}$ as well as an unidentified metabolite [22]. Due to the high concentrations of iAs ${ }^{\mathrm{III}}$ in the feces in comparison to urine, the authors inferred a significant contribution of the intestinal microbiocenosis to the demethylation and thereby toxification of DMAs $\mathrm{V}$.

Furthermore, two additional unidentified metabolites were detected in a follow-up study after oral administration of MMAs ${ }^{\mathrm{V}}$, DMAs ${ }^{\mathrm{V}}$, and TMAsO [23]. The formation of these compounds (named M-1, M-2, and M-3) and the involvement of the intestinal microbiocenosis was studied in more detail. Comparing the metabolism of DMAs $\mathrm{V}$, the authors found threefold higher concentrations of these unidentified metabolites after oral administration than after intraperitoneal administration [24]. Furthermore, these compounds were also mainly excreted as fecal metabolites, thereby again indicating an involvement of the intestinal microbiota. Moreover, the inhibition of glutathione (GSH) synthesis by L-buthionine-SR-sulfoximine (BSO) did not influence As biotransformation, even though GSH is an important cofactor in the endogenous As methylation [25]. In addition, in a parallel study the capability of Escherichia coli strains isolated from rat cecal contents after long-term oral administration of DMAs ${ }^{\mathrm{V}}$ to produce M-2, M-3 and TMAsO from DMAs ${ }^{\mathrm{V}}$ and M-1 from TMAsO was demonstrated [26]. Cysteine, but not GSH, was shown to be an important cofactor in microbial biotransformation of DMAs ${ }^{\mathrm{V}}$.

The molecular weight of the three unidentified As species M-1, M-2, and M-3 was determined by LC-MS as 152, 154, and $170 \mathrm{Da}$, and their molar ratios of As to $S$ was 1:1, 1:1, and 1:2, respectively $[27,28]$. After reaction with hydrogen peroxide, M-2 and M-3 yielded DMAs ${ }^{\mathrm{V}}$ and $\mathrm{M}-1$ yielded TMAsO. Though the identity of these species was not determined unambiguously in these studies, by comparison of this data with recent studies it can be derived that M-2 described by the group from Osaka City University Medical School is identical to dimethylmonothioarsinic acid $\left[\left(\mathrm{CH}_{3}\right)_{2} \mathrm{As}(=\mathrm{S}) \mathrm{OH}\right.$, DMMTAs ${ }^{\mathrm{V}}$ ] identified by Hansen et al. [29], as it was prepared in both studies with the same procedure by Reay and Asher (reaction of DMAs ${ }^{\mathrm{V}}$ with metabisulfite-thiosulfate reagent) [30] and showed the same molecular mass (154) and similar LC-MS/MS fragmentation pattern. Hansen et al. identified DMMTAs ${ }^{\mathrm{V}}$ in urine and wool of sheep eating seaweed containing naturally high concentrations of arsenosugars. Furthermore, dimethyldithioarsinic acid $\left[\left(\mathrm{CH}_{3}\right)_{2} \mathrm{As}(=\mathrm{S}) \mathrm{SH}\right.$, DMDTAs ${ }^{\mathrm{V}}$, MW 170] was prepared by both Hansen et al. and Suzuki et al. by bubbling DMAs ${ }^{\mathrm{V}}$ with gaseous $\mathrm{H}_{2} \mathrm{~S}$, which can be considered identical to M-3 on the basis of data available as proposed by Suzuki et al. [31]. In the case of M-1, it can be derived from the facts that this compound is a sulfur-containing derivative of TMAsO with the molecular mass of 152 , that the compound is trimethylarsine sulfide $\left[\left(\mathrm{CH}_{3}\right)_{3} \mathrm{AsS}\right.$, TMAsS $]$.

The thiolation of DMAs ${ }^{\mathrm{V}}$ and TMAsO by mouse cecal contents was verified in a recent study [32]. One to two minutes after addition of DMAs ${ }^{\mathrm{V}}$, conversion to DMMTAs ${ }^{\mathrm{V}}$ and DMDTAs ${ }^{\mathrm{V}}$ was detectable; after $24 \mathrm{~h}, \mathrm{DMAs}^{\mathrm{V}}$ was quantitatively converted to DMMTAs ${ }^{\mathrm{V}}$, DMDTAs ${ }^{\mathrm{V}}$ as well as TMAsS. TMAsO was almost quantitatively converted to TMAsS within $1 \mathrm{~h}$. Three chromatographic separations were utilized to verify the lack of co-elution prior to quantification by ICP-MS, and the identities of all three thiolated metabolites were confirmed with HPLC-ESI-MS/MS. Furthermore, in a 
follow-up study, incubation of ${ }^{34} \mathrm{~S}$ labeled DMMTAs ${ }^{\mathrm{V}}\left({ }^{34} \mathrm{~S}\right.$-DMMTAs $\left.{ }^{\mathrm{V}}\right)$ with anaerobic microbiota of mouse cecum yielded ${ }^{34} \mathrm{~S}$-TMAsS, thereby indicating that thiolated compounds can be methylated directly without the need of intermediate conversion toward the oxoforms [33].

Although it can be concluded from these studies that intestinal microorganisms play an important role in producing thiolated metabolites of $\mathrm{DMAs}^{\mathrm{V}}$ [28], subsequent studies showed that the endogenous metabolism of mammalian cells is also capable of forming these species. After addition of DMAsIII, but not $\mathrm{DMAs}^{\mathrm{V}}$ to rat liver supernatant, Suzuki et al. were able to identify the formation of DMDTAs ${ }^{\mathrm{V}}$ by thiolation and first reported the formation of dimethylthioarsinous acid $\left[\left(\mathrm{CH}_{3}\right)_{2} \mathrm{AsSH}\right)$, DMTAs $\left.{ }^{\mathrm{III}}\right]$ from DMAs ${ }^{\mathrm{III}}$, but later corrected their finding to DMMTAs ${ }^{\mathrm{V}}[31,34]$. Furthermore, DMDTAs ${ }^{\mathrm{V}}$ was detected in vivo in liver of rats 5 min after injection of MMAs ${ }^{\mathrm{III}}$ and DMAs ${ }^{\mathrm{V}}$ [28]. After addition of DMAs ${ }^{\mathrm{III}}$, both DMMTAs ${ }^{\mathrm{V}}$ and DMDTAs ${ }^{\mathrm{V}}$ were detected. Studying the uptake and transformation by rat and human red blood cells (RBCs), Naranmandura et al. were able to show that human RBCs are able to transform DMAs ${ }^{\mathrm{III}}$, but not DMAs ${ }^{\mathrm{V}}$ to DMDTAs ${ }^{\mathrm{V}}$ [35].

The cytotoxicity of thiolated methylarsenicals was investigated in several studies. DMMTAs $\mathrm{V}$ (M-2) was shown to be highly cyto- and genotoxic [28]. This was confirmed by Raml et al. and Naranmandura et al., who showed that the toxicity of this compound is close to that of the most toxic As species, iAsIII and DMAsIII [36,38], and, in case of human bladder cancer cells even significantly more cytotoxic than iAs ${ }^{\mathrm{III}}$ [37]. The increase of toxicity was mainly attributed to the larger cellular uptake, followed by its transformation to DMAs ${ }^{\mathrm{V}}$ and to the production of reactive oxygen species (ROS) in the redox equilibrium between DMAs ${ }^{\mathrm{V}}$ and DMAs ${ }^{\mathrm{III}}$ in the presence of glutathione [38].

The relevance of the formation of thiolated methylarsenicals was underlined by the detection of DMMTAs $\mathrm{V}$ in urine samples from Japanese men and As-exposed women in Bangladesh [36,39]. Following a single oral dose of iAs ${ }^{\mathrm{III}}$, DMMTAs ${ }^{\mathrm{V}}$ and DMDTAs ${ }^{\mathrm{V}}$ were detected in the urine of hamsters whereas DMMTAs ${ }^{\mathrm{V}}$ as well as MMMTAs ${ }^{\mathrm{V}}$ [monomethylmonothioarsonic acid, $\left.\mathrm{CH}_{3} \mathrm{As}(=\mathrm{S})(\mathrm{OH})_{2}\right]$ were detected in the urine of rats [40].

Very recently, the formation of methylated thioarsenicals by intestinal microbiota starting from inorganic As was shown. In vitro digestion of $i \mathrm{As}^{\mathrm{V}}$ under gastric and intestine conditions, followed by the incubation with in vitro cultured human colon microbiota resulted in significant methylation and thiolation [41]. After $24 \mathrm{~h}$ of colon incubation, iAs ${ }^{\mathrm{V}}(225 \mu \mathrm{g} / \mathrm{l})$ was converted to MMMTAs $\mathrm{V}^{\mathrm{V}}(43.7 \mu \mathrm{g} / \mathrm{l})$ besides MMAs ${ }^{\mathrm{V}}(31 \mu \mathrm{g} / \mathrm{l})$ and MMAs ${ }^{\mathrm{III}}(4.5 \mu \mathrm{g} / \mathrm{l})$, indicating both a highly efficient methylation of roughly $20 \%$ and a domination of thiolated metabolites from microbial intestinal metabolism. Addition of nutritional components under fed conditions lowered the fraction of soluble As species. Yet, of the soluble species, methylated and thiomethylated arsenicals were proportionally more abundant than those under fastung conditions. Interestingly, the presence of a soil matrix did not lower the potency to form methylated thioarsenicals. Given the hydrophobicity of these metabolites, intestinal transport across the colon epithelium is considered feasible. Hence, these data underline that intestinal microorganisms may also trigger the production of methylated thioarsenicals in the human body.

Finally, the thiolation of an arsenosugar by rat cecal contents has been reported. $95 \%$ of the arsenosugar tested was converted to its sulfur analog within $1 \mathrm{~h}$ [42]. Hansen et al. have reported the formation of thio-arsenosugars from arsenosugar-containing seaweed extracts by lamb liver cytosol [43]. Both the toxicity and the relative contribution of intestinal biotransformation of arsinothioyl-sugars are still unknown.

\section{Contribution of intestinal As biotransformation to overall metabolism and toxicity of As}

Despite the ability of gut bacteria to reduce and methylate inorganic As, clearly the main site of methylation in mammals is the liver. The protein which catalyzes the oxidative methylation of trivalent arsenicals, as well as the reduction of pentavalent arsenicals, was identified as the As ( +3 oxidation state) 
methyltransferase (AS3MT) [44]. In vivo studies in rats have shown that reduction and methylation of inorganic As is extremely rapid, $1 \mathrm{~h}$ after both oral or intravenous administration As was predominantly present in methylated forms [45]. Furthermore, methylation of As was similar in germ-free and conventional mice with normal intestinal microbiota after oral administration of arsenate, indicating that methylation of As by intestinal microorganisms contributes little to the overall methylation in vivo [46].

Concerning the role of intestinal microbiota, it was therefore concluded that the intestinal microbiota does not play a major role in methylation of As, as due to the rapid absorption of arsenate and arsenite in the small intestine [47], the interaction of gut bacteria and ingested inorganic arsenicals is limited [48].

Although the contribution of intestinal As methylation in the animal studies conducted was negligible due to the complete absorption of the soluble As species in the small intestine, the case is different if the bioavailability of ingested As is lower, and therefore the microbiota of the colon can come into contact with As species. Most notably, recent in vivo studies using the swine model system have shown that the bioavailability of As in rice, the most important source of exposure to As worldwide, is highly dependent on its initial speciation and preparation [49]. While the bioavailability of DMAs $\mathrm{V}$ from rice was low (33\%), bioavailability of rice cooked in water with iAs ${ }^{\mathrm{V}}$ was high $(89 \%)$.

Furthermore, As uptake is dependent on speciation as well as the presence of other food constituents. Gonzalez et al. demonstrated that uptake of pentavalent As is carried out by a saturable transport process and that addition of phosphate markedly decreased As absorption, most likely because $\mathrm{iAs}^{\mathrm{V}}$ and phosphate can share the same transport mechanism [50]. Ou et al. illustrated the binding capacity of wheat bran fibers toward $\mathrm{Hg}, \mathrm{Cd}$, and $\mathrm{Pb}$ and found microbial fiber fermentation in the colon to release part of the heavy metal ions [51]. Cooking of food can significantly alter the levels as well as the speciation of As in food [52-55].

The microbial matrix interference in the gut also includes oral exposure to contaminated soils. Exposure to soil-bound As is a worldwide problem due to locally high natural background levels of As as well as anthropogenic activities. The bioavailability of As from soils ranged from 0.6 to $68 \%$ when tested in various animal models [56]. Similarly, the relative oral bioavailability in male cynomolgus monkeys from As-contaminated soils ranged from 5 to $31 \%$ [57]. In order to study the effect of intestinal microbiota toward As bioaccessibility from mine tailings, Laird et al. performed a three-step sequential digestion. Here, soil samples that had gone through a gastric and small intestine phase, were subsequently incubated with colon bacteria for $18 \mathrm{~h}$ [58]. Their results showed that the colon microbiota were capable of increasing the bioaccessible As fraction with a factor of 3 vs. that of the gastric/intestine digest. Inactivation of colon microbiota by heat sterilization did not display an increase in bioaccessibility, indicating that active microbiota are involved. The proposed mechanisms for the observed bioaccessibility increase were dissimilatory As reduction or dissimilatory Fe reduction, the latter process allowing the release of As that is sorbed to Fe minerals such as ferrihydrite [58].

Considering these data, an influence of intestinal microorganisms on bioaccessibility of ingested As has to be suspected. Mechanisms can involve either a change of As speciation itself or degradation of As-binding constituents like Fe minerals or dietary fibers. Therefore, the role of intestinal microbiota needs to be addressed in assessing the bioavailability of As as well as other metal(loid)s.

In addition to biotransformation of ingested metal(loid)s, intestinal microorganisms can metabolize metal(loid)s entering the intestine via the enterohepatic cycle. In a comprehensive study, urinary and biliary excretion of intravenously administrated arsenate and arsenite was compared for five bile duct-cannulated animal species [59]. In contrast to pentavalent species, both arsenite as well as its metabolite MMAs ${ }^{\mathrm{III}}$ were preferentially excreted via the bile in rats, mice, hamsters, and guinea pigs but not in rabbits.

While the modulation of As bioavailability is one potential effect of intestinal microbiota, the production of toxic metabolites is another important issue. In particular, the thiolation is a highly relevant process, as DMMTAs ${ }^{\mathrm{V}}$ is much more efficiently taken up by cells and significantly more toxic in comparison to its oxo-analog, $\mathrm{DMAs}^{\mathrm{V}}$ [35,36]. From the in vivo studies with rats [22-24] as well as the in 
vitro studies with mice ceca [32] and cultured human colon microbiota [41] it can be inferred that the formation of methylated thioarsenicals can entirely take place in the gut lumen. The large intestine is generally rich in sulfides due to the presence of sulfate reducers. It could therefore be a site where methylation is followed by microbially triggered thiolation. Data show relatively high metabolic efficiencies of the gut microbiota ( $10 \%$ starting from ppb levels of iAs ${ }^{\mathrm{V}}$ ).

The rapid formation of methylated thioarsenicals after injection of methylarsenicals to rats in vivo [28] indicates that an endogenous pathway also must exist, but the exact production mechanism is not known. Liver cell supernatant, but not intact hepatic cell was able to produce methylated thioarsenic species. It is hypothesized that hepatic DMAs ${ }^{\mathrm{III}}$ is converted by RBCs to DMMTAs ${ }^{\mathrm{V}}$ [35], yet these findings could not be generalized over different higher organisms (humans vs. rats). The relative importance of intestinal and endogenous thiolation cannot be derived from present data, but it is clear that it will crucially depend on the chemical form of As, the matrix as well as the animal species.

Finally, the formation of volatile As species is another interesting feature of microbial metalloid metabolism. Due to their ability to easily cross cell membranes, volatile species could affect completely different target organs than nonvolatile species.

\section{INTESTINAL METHYLATION AND DEMETHYLATION OF Hg}

The different aspects of interaction between the intestinal microbiome and $\mathrm{Hg}$ has been reviewed comprehensively by Rowland [48].

The biological methylation of $\mathrm{Hg}$ in the human intestine has been proposed and investigated already early. After incubations of both human fecal samples and rat cecal contents with $\mathrm{HgCl}_{2}$, small amounts of $\mathrm{MMHg}$ were detected [60,61]. After sterilization of rat cecal contents, only minimal methylation was observed [61]. For several pure cultures of intestinal microorganisms derived from rats and humans, methylation of $\mathrm{Hg}$ was observed [61,62].

While these results have to be interpreted with caution due to the artifact-prone analytical protocols used in these studies, in particular the Westoo method [63], it is reasonable to assume that $\mathrm{Hg}$ in principle can be methylated in the human intestine. Sulfate-reducing bacteria (SRB), which are the most important methylating microorganisms in the environment [64,65], are common members of the human intestinal microbial community [66]. It is therefore possible that $\mathrm{Hg}$ can be methylated in the human intestine. As Hg methylation is inhibited by the high sulfate concentrations due to the reduced availability of inorganic $\mathrm{Hg}$ [67], the rate of methylation is presumably low and very dependent on the nutrition. Furthermore, due to the exposure to methylmercury $\left[\mathrm{CH}_{3} \mathrm{Hg}^{+}, \mathrm{MMHg}\right]$ via seafood, the intestinal methylation is presumably of lesser relevance for this element. Nevertheless, due to the exposure to inorganic $\mathrm{Hg}$ in terrestrial foodstuff and the low absorption of inorganic $\mathrm{Hg}$ in the small intestine, there is a need to investigate the extent of $\mathrm{Hg}$ methylation with a combination of modern analytical techniques and broader proband cohort studies.

Whereas the methylation of $\mathrm{Hg}$ is presumably of lesser toxicological relevance, in contrast, the capability of intestinal microorganisms to demethylate $\mathrm{Hg}$ has been proposed to be of central importance for the elimination of MMHg $[48,68]$. MMHg undergoes enterohepatic cycling with excretion in bile, reabsorption from the gastrointestinal tract, and by portal circulation return to the liver [69], which contributes to the long biological half-life [70]. Demethylation of MMHg by intestinal bacteria, which has been shown in several studies [60,71-73], can interrupt enterohepatic circulation and thereby aid fecal excretion $[3,68]$.

The significance of this process for the elimination of MMHg has been demonstrated in a number of studies [74]. The relative proportion of inorganic $\mathrm{Hg}$ in feces and large intestinal contents was less in germ-free mice [75], antibiotic-treated mice [73,76] and rats [77], and cecum-resected mice [78] than in control animals. Treatment with antibiotics increased the half-life of MMHg in mice from 6 days in control animals to more than 100 days [73]. The small and large intestinal absorption of MMHg was studied by Seko et al. [74]. Antibiotic-treated and control mice were administered MMHg intra- 
peritoneally and after $24 \mathrm{~h}$ the contents of small intestine and cecum were sampled. Then, these contents were placed into cecum and colon resected from untreated mice and the release of $\mathrm{Hg}$ from closed tracts was studied after $2 \mathrm{~h}$ incubation in vitro. Due to the reduced demethylation in antibiotic-treated animals, colon absorption was significantly higher in comparison to control animals (57 vs. $37 \%$ ), thereby indicating that decomposition of $\mathrm{MMHg}$ by gut microorganisms decreases the intestinal reabsorption rate of MMHg in vivo.

Composition of the microbiota in different developmental stages was shown to influence the $\mathrm{MMHg}$ demethylation capacity [79]. Fecal suspensions from suckled infants demethylated $\mathrm{MMHg}$ much slower than those from older children, and feces from children aged 10 months on a milk diet also showed a lower rate of demethylation than those from children of similar age consuming solid diets. This implies that unweaned infants are more susceptible to the toxic effects of MMHg than adults.

\section{IN VIVO AND EX VIVO STUDIES ON INTESTINAL BI VOLATILIZATION}

The biotransformation of $\mathrm{Bi}$ was investigated in a series of studies both with human probands as well as mice in vivo and ex vivo. In a pilot study with three volunteers, the formation of volatile Bi species was observed after ingestion of colloidal Bi subcitrate (CBS) containing $215 \mathrm{mg} \mathrm{Bi}$ [80]. CBS is a pharmaceutical used as treatment for peptic ulcers and irritable bowel syndrome (IBS) as well as for the eradication of Helicobacter pylori [81]. As the production of volatile Bi species was also shown for fecal samples incubated anaerobically ex vivo, this process was studied in detail.

In a follow-up study with 20 male human volunteers administered the same dose of CBS, the uptake, metabolism, and excretion of Bi was investigated [82]. Total Bi concentrations in blood increased rapidly in the first hour following ingestion, but overall $\mathrm{Bi}$ absorption in the stomach and upper intestine was very low, as evidenced by the small quantity $(0.03-1.2 \%)$ of Bi eliminated via the renal route. The evolution of volatile trimethylbismuth $\left[\left(\mathrm{CH}_{3}\right)_{3} \mathrm{Bi}\right.$, TMBi] was followed both in the breath as well as the blood by low-temperature (LT)-GC-ICP-MS. Breath and blood concentrations showed a correlating time-pattern with low to non-detectable concentrations within the first $2 \mathrm{~h}$ and maximum concentrations ranging from 0.8 to $458 \mathrm{ng} / \mathrm{m}^{3}$ reached after 8 or up to $68 \mathrm{~h}$ after ingestion. The delayed formation of this metabolite indicates the involvement of the intestinal microbiota. A maximum of $0.03 \%$ of the ingested dose was exhaled in this study.

Similar to the pilot study, volatilization of Bi was observed for fecal samples incubated anaerobically ex vivo [83]. In accordance to the in vivo results, volatilization rates showed a high inter-individual variation comprising several orders of magnitude. Interestingly, trace amounts of volatile As, Sb, $\mathrm{Te}, \mathrm{Pb}$, and $\mathrm{Bi}$ species were detected in the headspace of non-amended fecal samples. Though total concentrations of other metal(loid)s were not increased by CBS administration, higher concentrations as well as small amounts of volatile Sn species were found post-application of CBS, indicating an induction of the methylation of other metal(loid)s by Bi [83].

In addition to the delayed formation of TMBi in the proband studies and the ex vivo capability of stool samples to generate TMBi, another strong indication that the intestinal microbiocenosis is able to methylate Bi under in vivo conditions was the detection of significant amounts of TMBi in freshly collected feces (unpublished results).

In an accompanying study, the role of the gut microbiota in biovolatilization of metal(loid)s was investigated using both conventionally raised and germ-free mice and the volatilization capacity from contents of the different gut segments (small intestine, cecum, and large intestine) was studied [83]. While in-gut segments from germ-free mice no methylation was observed, methylation of $\mathrm{Bi}$ was observed in all segments of conventionally raised mice. The highest methylation rates were observed in the cecum followed by the large intestine.

Although these data clearly indicate that $\mathrm{Bi}$ is methylated in the human gut, the current data show that the participation of an endogenous enzymatic pathway, in particular by the human liver, cannot be 
ruled out. The formation of monomethylbismuth, but not di- or trimethylbismuth by hepatic cell cultures was shown by Hollmann et al. [84].

\section{COMPARATIVE INVESTIGATION OF VOLATILIZATION OF METAL(LOID)S BY INTESTINAL MICROORGANISMS}

The capability of 14 bacterial (members of Proteobacteria, Firmicutes, Actinobacteria, and Bacteriodetes) as well as two methanoarchaeal (Methanobrevibacter smithii and Methanosphaera stadtmanae) human gut inhabitants to produce volatile derivates from inorganic $\mathrm{As}, \mathrm{Se}, \mathrm{Sb}, \mathrm{Te}, \mathrm{Hg}$, and $\mathrm{Bi}$ salts was studied [85]. Volatilization was observed for all elements, whereas for $\mathrm{Hg}$ only elemental $\mathrm{Hg}^{0}$ was found in the headspace of both sterile and non-sterile samples. Bacterial strains were only capable to generate permethylated species of $\mathrm{Se}, \mathrm{Te}, \mathrm{Sb}$, and $\mathrm{Bi}$. In addition to these species, the methanoarchaeal human gut inhabitants produced methyl and hydride species of As and Bi as well as thiomethyl $\left(\mathrm{CH}_{3} \mathrm{~S}-\right)$ of Se. Similar species patterns were observed for methanoarchaea isolated from other environments. In addition to the broader species spectrum, the volatilization rates of methanoarchaeal strains were one to two orders of magnitude higher in comparison to the bacterial strains investigated in this study.

Due to the more diverse spectrum and higher production rates of methanoarchaeal strains, the authors inferred that methanoarchaea play an essential role in the transformation processes also in the human gut. However, in the ex vivo studies with mice and human fecal samples, the production of volatile metal(loid) derivatives did not correlate with methane production [83]. Furthermore, reinfected mice showed comparable TMBi production but considerably lower methane production than conventionally raised mice, which indicated that other than methanoarchaea contribute to the metal(loid) derivatization of the intestine [83].

In order to compare the biotransformation capacity of the intestinal microbiocenosis for different elements, two studies were conducted investigating the volatilization from inorganic salts of Ge, As, Se, $\mathrm{Sn}, \mathrm{Sb}, \mathrm{Te}, \mathrm{Hg}, \mathrm{Pb}$, and $\mathrm{Bi}$ amended to either fresh fecal slurries [86] or to the microbiocenosis from different compartments of the SHIME system [87]. The SHIME (Simulator of the Human Intestinal Microbial Ecosystem) is an in vitro gastrointestinal model developed to mimic the microbial community present in the human colon [88]. The SHIME mimics several physicochemical, enzymatic, and especially microbiological processes that occur in the human gut. It allows the control of stomach $\mathrm{pH}$, small intestine bile salt, and enzyme concentrations as well as the investigation of human colon microbiota metabolism at different $\mathrm{pH}, \mathrm{Eh}$, and residence time values.

In both studies, in particular $\mathrm{As}$, but also $\mathrm{Se}, \mathrm{Te}, \mathrm{Sb}$, and $\mathrm{Bi}$ were volatilized by intestinal microorganisms. In addition to methyl- and hydride species, a range of more complex As and selenium species was detected in the headspace of fecal incubations. By combined use of molecular and elemental detection after gas chromatographic separation (GC-EI-MS/ICP-MS) as well as synthesis experiments, these compounds were identified as methylthio species [dimethyl-methylthio-arsine, $\left(\mathrm{CH}_{3}\right)_{2} \mathrm{AsSCH}_{3}$ methyl-di(methylthio)-arsine, $\mathrm{CH}_{3} \mathrm{As}\left(\mathrm{SCH}_{3}\right)_{2}$, methyl-methylthio-selenide, $\mathrm{CH}_{3} \mathrm{SeSCH}_{3}$, di(methylthio)-selenide $\left(\mathrm{CH}_{3} \mathrm{~S}\right)_{2} \mathrm{Se}$ ], methyldithio species, [dimethyl-methyldithioarsine, $\left(\mathrm{CH}_{3}\right)_{2} \mathrm{AsSSCH}_{3}$, methyl-methyldithio-selenide $\mathrm{CH}_{3} \mathrm{SeSSCH}_{3}$ ] as well as methyl-methylthioethylthio-arsine $\left[\mathrm{CH}_{3} \mathrm{As}\left(\mathrm{SCH}_{3}\right)\left(\mathrm{SC}_{2} \mathrm{H}_{5}\right)\right]$, dimethylthioarsinous acid, $\left[\left(\mathrm{CH}_{3}\right)_{2} \mathrm{AsSH}\left(\mathrm{DMTAs}{ }^{\mathrm{III}}\right)\right]$, and thio-bis(dimethylarsine) $\left\{\left[\left(\mathrm{CH}_{3}\right)_{2} \mathrm{As}\right]_{2} \mathrm{~S}\right\}$. Furthermore, one mixed As/Se compound, dimethylmethylseleno-arsine $\left[\left(\mathrm{CH}_{3}\right)_{2} \mathrm{AsSeCH}_{3}\right]$ was identified. The toxicity of these compounds is unknown.

Using the SHIME system, a comprehensive study was conducted, investigating the volatilization of metal(loid)s in dependence of metal(loid) concentration, oxidation state of the inorganic metal(loid) amended as well as the colon region [87]. Amending different levels of a multi-element spike, both As and Te showed a near-linear increase in volatilization in the range of 10 to $500 \mu \mathrm{g}$ (per element)/l leveling off for 1000-5000 $\mu \mathrm{g} / \mathrm{l}$. Inter-element cross-influence was observed for As and Se, as volatilization of As was inhibited by high concentrations of Se, whereas volatilization of Se was not affected by 
As concentration. The initial oxidation of the elements seems to play little role on the volatilization rate, probably due to the strongly reducing conditions in the colon.

The highest volatilization rates were detected in the ascending colon in accordance with the higher microbial activity in this compartment. Surprisingly, the dominant As species detected in batches with rectum suspension was arsine $\left[\mathrm{AsH}_{3}\right]$, whereas methylthio species were dominant in the preceding compartments of the colon. By comparison with sterilized batches, the authors inferred that the volatilization of the elements investigated is predominantly caused by biological processes.

Volatilization rates in the experiments with the SHIME system were relatively low, maximal hourly production rates relative to the amount spiked were $0.6,2$, and $9 \mathrm{ng} \mathrm{mg}^{-1} \mathrm{~h}^{-1}$ for Se, As, and Te, respectively. In comparison, volatilization by fresh fecal slurries was more efficient ranging up to $0.5 \%$ of the arsenate amended within $48 \mathrm{~h}$, equivalent to $100 \mathrm{ng} \mathrm{mg}^{-1} \mathrm{~h}^{-1}$ [87]. Surprisingly, no volatilization was observed from inorganic $\mathrm{Sb}$ and $\mathrm{Bi}$ salts. In contrast, the volatilization of these metal(loid)s from a soil matrix was shown [87].

\section{INTESTINAL METHYLATION OF Se AND Te}

Se is an essential metal(loid), which forms the active center for a range of selenoproteins by human cells $[89,90]$. The enzyme responsible for biomethylation of Se is primarily located in the cytosol of lung and liver cells [91,92]. In the last years, selenosugars have been identified as the major urinary Se metabolite [89]. Furthermore, dimethylselenide $\left[\left(\mathrm{CH}_{3}\right)_{2} \mathrm{Se}, \mathrm{DMSe}\right]$ is exhaled in breath as early as $15 \mathrm{~min}$ after ingestion [93].

The effect of the oral administration of L-selenomethionine (SeMet) $(2 \mathrm{mg} / \mathrm{kg}$ feed) on the metabolic activity measured by the short-chain fatty acid concentration in different sections of the rat gut was studied [94]. SeMet significantly increased fermentation in the colon and rectum, but not in the cecum or feces, and some $50 \%$ of the Se was associated with colonic microbes and $58 \%$ in fecal microbes. These results indicate on the one hand that the ingestion of metal(loid)s can influence the metabolic activity of the intestine and on the other hand that intestinal microbiota can modulate the bioaccessibility of Se through binding of Se.

For Te, which is in the same periodic group, much less information is available. Dimethyltelluride $\left[\left(\mathrm{CH}_{3}\right)_{2} \mathrm{Te}, \mathrm{DMTe}\right]$ has been known for a long time as the garlic-like odor of mine workers and patients treated with Bi carbonate contaminated with Te (mistaken as "Bi breath") [95]. Biomethylation of Te by bacteria is relatively wide-spread [96,97]. In contrast, biotransformation mechanisms in humans are not yet known and analytical species validation is still lacking [3].

Te is a non-essential metalloid and was expected to be metabolized in the same pathway as in the case of an excess amount of the essential element Se [98]. In contrast, trimethyltelluronium $\left[\left(\mathrm{CH}_{3}\right)_{3} \mathrm{Te}^{+}\right.$, TMTe] was identified as the major urinary metabolite after oral administration of tellurite, suggesting that $\mathrm{Te}$ is discretely metabolized from Se [98].

Te is excreted mainly via feces when ingested and via the urine when given intraperitoneally or intravenously [99]. Animal studies suggest that only up to $25 \%$ of orally administered Te is absorbed from the gut, but various levels of absorption have been reported for different animal species [99]. In a recent study, fecal elimination was found to be higher for Te in comparison to Se (11.5\% resp. $0.9 \%$ of the ingested dose) after oral administration to rats [100].

In human investigations, the characteristic pungent garlic-like smell appeared $75 \mathrm{~min}$ after ingestion of $0.5 \mu \mathrm{g} \mathrm{TeO}$ and persisted for $30 \mathrm{~h}$, in case of $10 \mathrm{mg}$ ingestions after exposure [101]. Both the extremely long appearance of the garlic-like breath and the observation of garlic-like odor after injection of 20-30 mg elemental Te to rabbits [101] are indicative that endogenous production of DMTe is the dominant process in comparison to the contribution of intestinal biotransformation.

Although experiments with intestinal microbiota have shown that the intestinal microbiocenosis is capable of metabolizing Se and Te (see above), it cannot be derived at present time to what extent the intestinal metabolism is of significance for the overall metabolism of these two metal(loid)s. Due to the 
lower intestinal absorption of Te and the higher biotransformation rates in incubation experiments [87], a more significant contribution of intestinal biotransformation can be expected for Te than for Se.

\section{INTESTINAL BIOTRANSFORMARION OF OTHER METAL(LOID)S: Ge, Cd, In, Sn, Sb, TI, $\mathrm{Pb}$, AND Po}

$\mathrm{Sb}$ is readily methylated in the environment [102]. In experiments with bile duct-cannulated male Wistar rats, significant enterohepatic circulation for $\mathrm{Sb}$, but no methylated $\mathrm{Sb}$ species were observed in bile or urine samples [103]. In contrast, both in pure culture experiments with intestinal microorganisms [85] as well as incubation experiments with fresh fecal slurries [86] or microbiocenosis from the SHIME system [87], trimethylstibine $\left[\left(\mathrm{CH}_{3}\right)_{3} \mathrm{Sb}\right.$, TMSb] has been detected, which has been reported to be genotoxic [104]. Therefore, intestinal biomethylation of antimony is possible, but the significance for the overall metabolism cannot be derived from present data.

For $\mathrm{Sn}$ and $\mathrm{Pb}$, much information is available on the metabolism and excretion of methylated $\mathrm{Pb}$ and $\mathrm{Sn}$ species [3]. The only indication of potential biotransformation in the intestine was the detection of ultratrace amounts of volatile $\mathrm{Sn}$ and $\mathrm{Pb}$ species in fecal samples [83].

Considering other elements, which have been reported to undergo methylation in the environment, namely Ge, Cd, In, Tl, and Po, little to no data on the methylation in the human body or the involvement of the human intestinal microbiota exists.

An interesting candidate element for intestinal biomethylation is Po. ${ }^{210} \mathrm{Po}$, which has gained considerable attention after the intoxication of Alexander Litvinenko [105], is a naturally occurring radioisotope $\left(T_{1 / 2}=138.4 \mathrm{~d}\right)$ of the $\mathrm{U}$ radioactive series. ${ }^{210} \mathrm{Po}$ was estimated to contribute to $60 \%$ of the average world individual effective dose from ingestion of radionuclides from the $U$ and $T h$ series [106]. Human absorption of Po from foodstuffs is dependent on the food matrix and varies between 15 and $65 \%$ [106].

Polonium can be methylated abiotically by methylcobalamin [107] and has been shown to be volatilized from sea water and fresh water environments $[108,109]$. Furthermore, volatilization was observed by green bread mold [108] and pure cultures of $E$. coli cultivated under anaerobic conditions [110]. Therefore, it is possible that biomethylation can occur in the human intestine, and its contribution to the bioavailability and toxicity of this element needs to be investigated.

\section{CONCLUSIONS AND PROSPECTS}

The collection of literature data in this review shows that metal(loid) biotransformation by the intestinal microbial community can be considered a common process, carried out by a diverse group of bacterial species and taking place in the gut of presumably many higher organisms. The quintessential question, however, is whether gut microbial metal(loid) biotransformation matters in terms of risk assessment. In this final section, we want to place gut microbial metabolism into the perspective of direct health effects, and shortly provide an overview of the methodology that can be applied in future research to assess the importance of microbial metal(loid) metabolism.

\section{Comparison of intestinal biotransformation for different metal(loid)s}

As discussed throughout the course of this review, the risk of an ingested metal(loid) is highly defined by its speciation as this determines the fate in the body and eventual biological activity. Although the mechanism and process conditions for metal(loid) metabolism by gut microbiota remain to be elucidated, the current data seem to point to a highly differentiated picture depending on the metal(loid) under study.

For $\mathrm{Bi}$, the overall evidence implies a significant involvement of intestinal microbiota in methylation of this element. Both the delayed TMBi formation, the presence of high concentrations of the 
metabolite TMBi in the feces as well as the limited capability of hepatocytes to generate only MMBi, hint toward the colon as the main site of biomethylation of this element. Although relative conversion rates are low, the ability of TMBi to migrate through the body could be an approach to explain the cases of encephalopathy diagnosed in the 1970s in French and Australian patients [111]. Noteworthy, the studies on Bi show a large interindividual variability in the metabolic potency of the intestinal microbiota [82], which has also been observed in various studies aiming at the intestinal biotransformation of pharmaceuticals [8].

In case of As and Se, intestinal microorganisms are capable of generating both methylated species and more complex (mainly S-containing) species. When considering the methylation process alone, the toxicological potential appears to be small, as these elements undergo extensive methylation in the human body and the pentavalent methylated species like $\mathrm{MMAs}^{\mathrm{V}}$ and $\mathrm{DMAs}{ }^{\mathrm{V}}$ have a low toxicity. However, the finding of trivalent methylated species and especially the thiolation of methylarsenicals are processes of high toxicological relevance. Thiolated species, in particular DMMTAs ${ }^{\mathrm{V}}$, have been shown to be much more efficiently taken up by cells and produce ROS in the redox equilibrium between $\mathrm{DMAs}^{\mathrm{V}}$ and DMAs ${ }^{\mathrm{III}}$ in the presence of glutathione [38]. Considering the efficient thiolation of inorganic and in particular methylated As species, it is probable that intestinal microbiota contribute to the overall As toxicity, in particular when oral exposure takes place with a contaminated food or soil matrix. The limited release of As from these matrices in the upper intestine results in a larger availability of these compounds to the intestinal microbial metabolic potency. Moreover, the toxicology of volatile thiomethyl As species has to be investigated in future studies. These data on microbial As metabolism suggest that the gut microbial potency should be integrated into the current efforts to develop toxicokinetic models for As [112].

The importance of demethylation for elimination of $\mathrm{Hg}$ reminds us not only to investigate the new formation of metabolites, but also to assess the role of degradation of complex metal(loid) species, in particular for As and Se. In particular, studies on the interindividual variability of intestinal metabolism are required.

For both $\mathrm{Sb}$ and $\mathrm{Te}$, intestinal biomethylation has been shown, but the significance for the overall metabolism cannot be derived from present data. For the other metal(loid)s covered in this review, very little data is available to assess the potential role of intestinal biomethylation. Considering the experience of environmental biomethylation of these elements, Po in particular is an interesting candidate for intestinal biotransformation.

\section{Modulation of health effects}

The current knowledge on toxicokinetics of many metal(loid)s has been generated through so-called ADME studies, in which the absorption, distribution, metabolism, and excretion of a compound is monitored in an in vivo set-up [113-115]. Although mammalian metabolism is considered the primary pathway driving metal(loid) toxicity, it is important to realize that gut microbiota may interfere with all 4 ADME processes.

Firstly, due to the microbial reactivity toward the ingested contaminated matrix (reduction of soil minerals or fermentation of dietary fiber), the bioaccessibility of metal(loid)s in the gut lumen can be modulated by the gut microbiota. The latter results in changes in the amount which is transported across the gut epithelium and hence, also bioavailability. Such microbial interference with the ingested matrix was described by Laird et al. [58] and Ou et al. [51].

Secondly, the microbial volatilization of metal(loid)s $[83,86,87]$ suggests that the distribution of metal(loid)s over the body may be influenced by gut microbial activity. Due to their ability to easily cross cell membranes, volatile species can follow other transport pathways and affect different target organs than nonvolatile species. Furthermore, many volatile permethylated metal(loid) species ( $\mathrm{Hg}, \mathrm{Sn}$, $\mathrm{Pb}, \mathrm{Bi}$ ) show markedly neurotoxic effects [116]. 
Thirdly, we have seen throughout this review that intensive metal(loid) metabolism takes place by gut microbial activity. The absorption efficiency of these metabolites across the gut epithelium is not yet known, hence it is difficult to estimate their bioavailability. However, in vitro studies with Caco-2 cell cultures suggest that the absorption of methylated organoarsenicals (DMAs ${ }^{\mathrm{V}}: 10.0 \%$, TMAsO: $15.5 \%)$ is more efficient than that of $\mathrm{iAs}^{\mathrm{III}}(5.8 \%)$ and $\mathrm{iAs}^{\mathrm{V}}$ (max. 1.6\%) [87,117,118]. With respect to methylated thioarsenicals, there is no information available concerning their cross-epithelial transport. Yet, the hydrophobic character of these compounds makes them more prone to cellular uptake, which also causes their higher toxicity [38]. We therefore conclude that the uptake of microbial metal(loid) metabolites must be further studied and their contribution to total metal(loid) bioavailability assessed.

Fourthly, the microbial community in the gastrointestinal tract can also interfere with the excretion of metal(loid)s. Biliary secreted biotransformation metabolites reach the gut lumen and may become available to the enzymatic activity from the resident gut microbiota. For example, it has been shown that the demethylating capacity of gut microorganisms significantly decreases the reabsorption of $\mathrm{MMHg}$, whereas an elevated residence time of $\mathrm{Hg}$ in the body was observed for germ-free and antibiotic treated rats (see above). For Hg, microbial interference with the excretion of metal(loid)s has been recognized but is currently not integrated in toxicokinetic modeling [119].

The microbial involvement in all four ADME processes suggests that the metabolic potency from gut microorganisms may indeed affect the health risks associated with oral metal(loid) exposure. We do not assume that microbial metabolism generally pose an extra health risk, but we propose that we should at least not neglect their metabolic potency when developing new toxicokinetic models.

\section{Recommendations for future research}

To elucidate the gut microbial metabolic activity toward metal(loid)s, different experimental set-ups, each with their own advantages and disadvantages, come into consideration.

In vivo studies are physiologically most relevant and thus widely applied for ADME studies in which the absorption, distribution, metabolism, and excretion of ingested metal(loid)s is investigated. Human natural exposure studies and contaminant dosing studies with appropriate animal models may help to characterize the variety of metabolites that are formed and to identify relevant biomarkers following oral metal(loid) exposure. Yet, unless the finding of specific metabolites can be exclusively appointed to either mammalian metabolism or gut microbial metabolism, it is difficult to discern both metabolic pathways. In addition, common in vivo models are in essence "black boxes" that are not well suited to conduct mechanistic research on metal(loid) metabolism.

The use of germ-free animal models in combination with conventional or gnotobiotic animal models is very helpful to assess the contribution of gut microbiota to the altered speciation of ingested metal(loid)s. Indeed, germ-free animals will only metabolize the element of interest through the mammalian pathway, whereas conventional animals allow metal(loid) metabolism through both the mammalian as the gut microbial pathway. Interestingly, gnotobiotic animal models make it possible to colonize a germ-free animal with a microbial inoculum of interest: a combination of pure bacterial strains or entire microbial communities isolated from fecal samples or intestinal contents. Such an approach has previously been applied to characterize the gut microbial conversion of hop isoxanthohumol into the powerful phytoestrogen 8-prenylnaringenin [120]. The application of germ-free and conventional(ized) animal models is a powerful tool to explore mammalian/gut microbial metal(loid) metabolism and to identify metabolites that are typical of microbial origin.

However, the limitation of many in vivo studies is that the analysis of serum, urine, breath, or even organ tissue samples is often insufficient to elucidate the exact mechanism behind the production of specific metabolites. To this end, in vitro methods may be helpful. These typically make use of the culture of mammalian cells such as hepatocytes (e.g., Hep G2), enterocytes (e.g., Caco-2), or other cells of interest, with which the metal(loid) biotransformation, epithelial transport, or toxicity mechanism 
can be studied. Likewise, the use of in vitro digestion technology is indispensable for characterizing the microbial metabolic potency in the gastrointestinal tract. Several in vitro gastrointestinal models have been successfully validated against in vivo data (e.g., [121,122]), yet these models only consider gastric and intestinal processes and their in vivo validation has primarily focused on bioaccessibility-bioavailability correlations. Particularly for elements, which undergo extensive microbial biotransformation, like As, the colon microbiota must be incorporated. The in vitro approach for investigating microbial metal(loid) metabolism can be characterized by different experimental setups.

Firstly, the existing interindividual variability in the microbial metabolic potency must be investigated. Several years ago, the National Institutes of Health (NIH) started an ambitious project, which has the aims of exploring the vast microbial community that interacts with the human host: the Human Microbiome Project [123]. The microbiome comprises, amongst others, genes that code for an enormous diversity of metabolic enzymes. Further detection and characterization of the responsible genes and the identification of involved microbial species will considerably contribute to the elucidation of microbial metabolic processes in the gastrointestinal tract and the consequences for human health. Scientific research in the line of microbial metal(loid) metabolism will significantly benefit from the newly acquired knowledge in the Human Microbiome Project. It becomes clear that the gut microbiota from every individual displays a unique metabolic profile toward metal(loid)s or other chemicals. In vivo studies with human probands showed a high inter-individual variance in the metabolic potency. This variability is characteristic for gut microbial metabolism and has previously been described with the biotransformation of ingested phytoestrogens [124,125]. Therefore, variability in intestinal biotransformation could also contribute to the observed large inter-individual differences in As metabolism [126]. This is certainly a variable that is inherent to gut microbial metabolism, and including it in a risk assessment process will be a challenging task.

Secondly, fecal inocula of interest can be further studied to explore the metabolism kinetics as such and to investigate which parameters of influence favor the microbial metabolism of metal(loid)s. Parameters such as redox potential, presence of sulfate or Fe minerals, dependence on initial speciation and concentration of metal(loid), interelement influences between metal(loid)s can be investigated both in a batch experimental set-up [87] as well as in a semi-continuous mode, which allows more rigorous parameter control. In the same line of research, an interesting option is to work with consecutive digestion steps subsequently mimicking gastric, intestine, and colon conditions [58].

Once the microbial metabolic potency of a specific microbial inoculum is characterized, it can be studied how the microbial community responds to a continuous exposure of metal(loid)s and whether there is an adaptation in terms of metabolic activity toward metal(loid)s. To meet these research objectives, more complex in vitro models of the gastrointestinal tract are needed. So far, only a few semicontinuous and dynamic models have been developed to study colon microbiota in detail $[88,127,128]$. Here, a microbial suspension from fecal origin is inoculated into reactor compartments that mimic the specific conditions in the ascending, transverse, and descending colon. As each colon compartment harbors a different microbial community, it can be studied whether metal(loid) metabolism depends on specific fermentation activities and is thus colon region dependent. For example, the thiolation of methylated arsenicals is a process that may depend on the activity of sulfate-reducing microorganisms in the gut $[32,41,42]$. In addition, Meyer et al. previously suggested that metal(loid) methylation maybe a process closely linked to methanogenic activity [85]. Such fermentative activities may be more active in specific colon regions. Dynamic gut models like the TNO Intestinal Model [128] or SHIME [88,129] are well suited to study these phenomena over the long term.

Finally, a last experimental in vitro approach that is worthwhile to mention, is a combined hepatocyte-gut microbiota model for studying the joint metabolism of pharmaceuticals and aromatic hydrocarbons. Laube et al. developed an elegant bi-compartmental model in which a semi-permeable polycarbonate membrane separated the "liver" compartment, in which hepatocytes were cultured, from the "gut" compartment, in which gut microorganisms were incubated in an anaerobized suspension [130]. The initial purpose of this model was to monitor hepatic metabolism of selected chemicals and reveal 
to what extent gut microbiota may metabolize the phase II biotransformation metabolites that are transported across the semi-permeable membrane to the "gut" compartment. It is perfectly feasible to approach this model from the other way around, namely, monitoring the formation of microbial metal(loid) metabolites, their transport across the membrane and eventual metabolism by hepatocytes.

Last, but not least, the use of appropriate analytical techniques is mandatory. Considering the vast metabolic potency of microorganisms and hence the versatility of metal(loid) species that can be formed, the use of powerful analytical methodology is required combining both the analysis of volatile and nonvolatile species. The questionable detection of several Se metabolites in human urine samples [131] and corrected identification of DMMTAs instead of DMAs ${ }^{\mathrm{III}}$ [29] reminded us of the complexity of metal(loid) speciation and the necessity of vigorous quality control. For identification of new metal(loid) metabolites, the combined use of element and molecular detection has proven to be a very powerful approach.

In the last few decades, awareness of the importance of intestinal biotransformation in the metabolism of pharmaceuticals has steadily increased [8]. Likewise, we are convinced that elucidating this process for metal(loid)s can significantly contribute to the understanding of human metabolism of meta(loid)s and therefore risk assessment from ingested metal(loid)s.

\section{REFERENCES}

1. P. J. Craig. Organometallic Compounds in the Environment, John Wiley, Chichester (2003).

2. J. S. Thayer. Appl. Organomet. Chem. 16, 677 (2002).

3. A. V. Hirner, A. W. Rettenmeier. In Organometallics in Environment and Toxicology, A. Sigel, H. Sigel, R. K. O. Sigel (Eds.), The Royal Society of Chemistry, Cambridge (2010).

4. R. Gebhardt, J. G. Hengstler, D. Muller, R. Glockner, P. Buenning, B. Laube, E. Schmelzer, M. Ullrich, D. Utesch, N. Hewitt, M. Ringel, B. R. Hilz, A. Bader, A. Langsch, T. Koose, H. J. Burger, J. Maas, F. Oesch. Drug Metab. Rev. 35, 145 (2003).

5. H. Y. N. Holman, R. Goth-Goldstein, D. Aston, M. Yun, J. Kengsoontra. Environ. Sci. Technol. 36, 1281 (2002).

6. A. L. Juhasz, E. Smith, J. Weber, M. Rees, A. Rofe, T. Kuchel, L. Sansom, R. Naidu. Chemosphere 69, 961 (2007).

7. W. B. Whitman, D. C. Coleman, W. J. Wiebe. Proc. Natl. Acad. Sci. USA 95, 6578 (1998).

8. T. Sousa, R. Paterson, V. Moore, A. Carlsson, B. Abrahamsson, A. W. Basit. Int. J. Pharm. 363, 1 (2008).

9. R. R. Scheline. Pharmacol. Rev. 25, 451 (1973).

10. M. Mikov. Eur. J. Drug Metabol. Pharmacokinet. 19, 201 (1994).

11. H. Okuda, K. Ogura, A. Kato, H. Takubo, T. Watabe. J. Pharmacol. Exp. Ther. 287, 791 (1998).

12. V. Puntoni. Annali D'Igiene (1917).

13. F. Challenger, C. Higginbottom. Biochem. J. 29, 1757 (1935).

14. I. R. Rowland, M. J. Davies. J. Appl. Toxicol. 1, 278 (1981).

15. W. R. Cullen, B. C. McBride, H. Manji, A. W. Pickett, J. Reglinski. Appl. Organomet. Chem. 3, 71 (1989).

16. L. L. Hall, S. E. George, M. J. Kohan, M. Styblo, D. J. Thomas. Toxicol. Appl. Pharmacol. 147, 101 (1997).

17. M. J. Herbel, J. S. Blum, S. E. Hoeft, S. M. Cohen, L. L. Arnold, J. Lisak, J. F. Stolz, R. S. Oremland. FEMS Microbiol. Ecol. 41, 59 (2002).

18. K. Hanaoka, T. Motoya, S. Tagawa, T. Kaise. Appl. Organomet. Chem. 5, 427 (1991).

19. V. Devesa, A. Loos, M. A. Suner, D. Velez, A. Feria, A. Martinez, R. Montoro, Y. Sanz. J. Agric. Food Chem. 53, 10297 (2005).

20. C. F. Harrington, E. I. Brima, R. O. Jenkins. Chem. Speciation Bioavailability 20, 173 (2008). 
21. E. Dopp, A. D. Kligerman, R. A. Diaz-Bone. In Organometallics in Environment and Toxicology, A. Sigel, H. Sigel, R. K. O. Sigel (Eds.), The Royal Society of Chemistry, Cambridge (2010).

22. H. Chen, K. Yoshida, H. Wanibuchi, S. Fukushima, Y. Inoue, G. Endo. Appl. Organomet. Chem. 10, 741 (1996).

23. K. Yoshida, Y. Inoue, K. Kuroda, H. Chen, H. Wanibuchi, S. Fukushima, G. Endo. J. Toxicol. Environ. Health, Part A 54, 179 (1998).

24. K. Yoshida, K. Kuroda, Y. Inoue, H. Chen, Y. Date, H. Wanibuchi, S. Fukushima. Appl. Organomet. Chem. 15, 539 (2001).

25. D. J. Thomas, J. X. Li, S. B. Waters, W. B. Xing, B. M. Adair, Z. Drobna, V. Devesa, M. Styblo. Exp. Biol. Med. 232, 3 (2007).

26. K. Kuroda, K. Yoshida, A. Yasukawa, H. Wanibuchi, S. Fukushima, G. Endo. Appl. Organomet. Chem. 15, 548 (2001).

27. K. Yoshida, K. Kuroda, X. Zhou, Y. Inoue, Y. Date, H. Wanibuchi, S. Fukushima, G. Endo. Chem. Res. Toxicol. 16, 1124 (2003).

28. K. Kuroda, K. Yoshida, M. Yoshimura, Y. Endo, H. Wanibuchi, S. Fukushima, G. Endo. Toxicol. Appl. Pharmacol. 198, 345 (2004).

29. H. R. Hansen, A. Raab, M. Jaspars, B. F. Milne, J. Feldmann. Chem. Res. Toxicol. 17, 1086 (2004).

30. P. F. Reay, C. J. Asher. Anal. Biochem. 78, 557 (1977).

31. K. T. Suzuki, B. K. Mandal, A. Katagiri, Y. Sakuma, A. Kawakami, Y. Ogra, K. Yamaguchi, Y. Sei, K. Yamanaka, K. Anzai, M. Ohmichi, H. Takayama, N. Aimi. Chem. Res. Toxicol. 17, 914 (2004).

32. K. M. Kubachka, M. C. Kohan, S. D. Conklin, K. Herbin-Davis, J. T. Creed, D. J. Thomas. J. Anal. At. Spectrom. 24, 1062 (2009).

33. K. M. Kubachka, M. C. Kohan, K. Herbin-Davis, J. T. Creed, D. J. Thomas. Toxicol. Appl. Pharmacol. 2, 137 (2009).

34. H. Naranmandura, N. Suzuki, K. T. Suzuki. Chem. Res. Toxicol. 19, 1010 (2006).

35. H. Naranmandura, K. T. Suzuki. Toxicol. Appl. Pharmacol. 227, 390 (2008).

36. R. Raml, A. Rumpler, W. Goessler, M. Vahter, L. Li, T. Ochi, K. A. Francesconi. Toxicol. Appl. Pharmacol. 222, 374 (2007).

37. H. Naranmandura, Y. Ogra, K. Iwata, J. Lee, K. T. Suzuki, M. Weinfeld, X. C. Le. Toxicol. Appl. Pharmacol. 238, 133 (2009).

38. H. Naranmandura, K. Ibata, K. T. Suzuki. Chem. Res. Toxicol. 20, 1120 (2007).

39. R. Raml, W. Goessler, K. A. Francesconi. J. Chromatogr., A 1128, 164 (2006).

40. H. Naranmandura, N. Suzuki, K. Iwata, S. Hirano, K. T. Suzuki. Chem. Res. Toxicol. 20, 616 (2007).

41. T. Van de Wiele, C. Gallawa, N. Basta, G. Dulaing, J. Creed, K. Bradham. Submitted to Environ. Health Perspect.

42. S. D. Conklin, A. H. Ackerman, M. W. Fricke, P. A. Creed, J. T. Creed, M. C. Kohan, K. HerbinDavis, D. J. Thomas. Analyst 131, 648 (2006).

43. H. R. Hansen, M. Jaspars, J. Feldmann. Analyst 129, 1058 (2004).

44. S. B. Waters, V. Devesa, M. W. Fricke, J. T. Creed, M. Styblo, D. J. Thomas. Chem. Res. Toxicol. 17, 1621 (2004).

45. I. R. Rowland, M. J. Davies. J. Appl. Toxicol. 2, 294 (1982).

46. M. Vahter, B. Gustafsson. In Proceedings of $3^{\text {rd }}$ Symposium on Trace Elements, M. Anke, H.-J. Schneider, C. Bruckner (Eds.), pp. 123-129, Abteilung Wissenschaftliche Publikationen der Friedrich-Schiller-Universität, Jena (1980).

47. M. Vahter. In Biological Effect of Arsenic, B. Fowler (Ed.), Elsevier Science, Amsterdam (1983).

48. I. R. Rowland. In Role of Gut Bacteria in Human Toxicology and Pharmacology, M. J. Hill (Ed.), Taylor \& Francis, London (1995). 
49. A. L. Juhasz, E. Smith, J. Weber, M. Rees, A. Rofe, T. Kuchel, L. Sansom, R. Naidu. Environ. Health Perspect. 114, 1826 (2006).

50. M. J. Gonzalez, M. V. Aguilar, M. C. M. Para. Vet. Hum. Toxicol. 37, 131 (1995).

51. S. Y. Ou, K. R. Gao, Y. Li. J. Agric. Food Chem. 47, 4714 (1999).

52. J. M. Laparra, D. Velez, R. Barbera, R. Farre, R. Montoro. J. Agric. Food Chem. 53, 8829 (2005).

53. J. M. Laparra, D. Velez, R. Montoro, R. Barbera, R. Farre. J. Agric. Food Chem. 51, 6080 (2003).

54. V. Devesa, D. Velez, R. Montoro. Food Chem. Toxicol. 46, 1 (2008).

55. J. M. Laparra, D. Velez, R. Montoro, R. Barbera, R. Farre. Appl. Organomet. Chem. 18, 662 (2004).

56. WHO. Arsenic and Arsenic Compounds, World Health Organization, Geneva (2001).

57. S. M. Roberts, J. W. Munson, Y. W. Lowney, M. V. Ruby. Toxicol. Sci. 95, 281 (2007).

58. B. D. Laird, T. R. Van de Wiele, M. C. Corriveau, H. E. Jamieson, M. B. Parsons, W. Verstraete, S. D. Siciliano. Environ. Sci. Technol. 41, 5542 (2007).

59. L. Csanaky, Z. Gregus. Comp. Biochem. Physiol. C, Toxicol. Pharmacol. 131, 355 (2002).

60. T. Edwards, B. C. McBride. Nature 253, 462 (1975).

61. I. R. Rowland, M. J. Davies, P. Grasso. Biochem. Soc. Trans. 5, 423 (1977).

62. I. R. Rowland, M. J. Davies, P. Grasso. Biochem. Soc. Trans. 3, 502 (1975).

63. G. Westoo. Acta Chem. Scand. 20, 2131 (1966).

64. G. C. Compeau, R. Bartha. Appl. Environ. Microbiol. 50, 498 (1985).

65. M. Ranchou-Peyruse, M. Monperrus, R. Bridou, R. Duran, D. Amouroux, J. C. Salvado, R. Guyoneaud. Geomicrobiol. J. 26, 1 (2009).

66. G. R. Gibson, G. T. Macfarlane, J. H. Cummings. J. Appl. Bacteriol. 65, 103 (1988).

67. T. Barkay, I. Wagner-Dobler. In Advances in Applied Microbiology, Vol. 57, pp. 1-52, Elsevier Academic Press, San Diego (2005).

68. K. L. Nuttall. Ann. Clin. Lab. Sci. 34, 235 (2004).

69. T. W. Clarkson, L. Magos, G. J. Myers. N. Engl. J. Med. 349, 1731 (2003).

70. J. F. Risher, E. H. Murray, G. R. Prince. Toxicol. Ind. Health 18, 109 (2002).

71. I. R. Rowland, M. J. Davies, P. Grasso. Xenobiotica 8, 37 (1978).

72. T. Norseth, T. W. Clarkson. Arch. Environ. Health 22, 568 (1971).

73. I. R. Rowland, R. D. Robinson, R. A. Doherty. Arch. Environ. Health 39, 401 (1984).

74. Y. Seko, M. Takahashi, T. Hasegawa, T. Miura. J. Health Sci. 47, 508 (2001).

75. I. Nakamura, K. Hosokawa, H. Tamura, T. Miura. Bull. Environ. Contam. Toxicol. 17, 528 (1977).

76. Y. Seko, T. Miura, M. Takahashi, T. Koyama. Acta Pharmacol. Toxicol. 49, 259 (1981).

77. I. R. Rowland, M. J. Davies, J. G. Evans. Toxicol. Lett. 78 (1980).

78. Y. Seko, T. Miura, M. Takahashi. Acta Pharmacol. Toxicol. 50, 117 (1982).

79. I. R. Rowland, R. D. Robinson, R. A. Doherty, T. D. Landry. In Reproductive and Developmental Toxicity of Metals, T. W. Clarkson (Ed.), Plenum Press, New York (1983).

80. A. V. Hirner, A. W. Rettenmeier. In Organometal and Organometalloid Species in the Environment: Analysis, Distribution, Processes and Toxicological Evaluation, A. V. Hirner, H. Emons (Eds.), pp. 97-112, Springer Verlag, Heidelberg (2004).

81. H. Sun, L. Zhang, K.-Y. Szeto. In Metal Ions and Their Complexes in Medication, A. Sigel, H. Sigel (Eds.), Marcel Dekker, New York (2004).

82. J. Boertz, L. M. Hartmann, M. Sulkowski, J. Hippler, F. Mosel, R. A. Diaz-Bone, K. Michalke, A. W. Rettenmeier, A. V. Hirner. Drug Metab. Dispos. 37, 352 (2009).

83. K. Michalke, A. Schmidt, B. Huber, J. Meyer, M. Sulkowski, A. V. Hirner, J. Boertz, F. Mosel, P. Dammann, G. Hilken, H. J. Hedrich, M. Dorsch, A. W. Rettenmeier, R. Hensel. Appl. Environ. Microbiol. 74, 3069 (2008).

84. M. Hollmann, J. Boertz, E. Dopp, J. Hippler, A. V. Hirner. Metallomics 2, 52 (2010).

85. J. Meyer, K. Michalke, T. Kouril, R. Hensel. Syst. Appl. Microbiol. 31, 81 (2008).

86. R. A. Diaz-Bone, M. Hollmann, O. Wuerfel, D. Pieper. J. Anal. At. Spectrom. 24, 808 (2009). 
87. R. A. Diaz-Bone, T. R. Van de Wiele. Environ. Sci. Technol. 43, 5249 (2009).

88. K. Molly, M. V. Woestyne, W. Verstraete. Appl. Microbiol. Biotechnol. 39, 254 (1993).

89. K. T. Suzuki. J. Health Sci. 51, 107 (2005).

90. L. Schomburg, U. Schweizer, J. Kohrle. Cell. Mol. Life Sci. 61, 1988 (2004).

91. N. M. Mozier, K. P. McConnell, J. L. Hoffman. J. Biol. Chem. 263, 4527 (1988).

92. K. Nakamuro, T. Okuno, T. Hasegawa. J. Health Sci. 46, 418 (2000).

93. D. Kremer, G. Ilgen, J. Feldmann. Anal. Bioanal. Chem. 383, 509 (2005).

94. J. Kim, G. F. Combs. Biol. Trace Elem. Res. 56, 215 (1997).

95. Feldmann. In Organometallic Compounds in the Environment, P. J. Craig, (Ed.), John Wiley, Chichester (2003).

96. T. G. Chasteen, R. Bentley. Chem. Rev. 103, 1 (2003).

97. D. Zannoni, F. Borsetti, J. J. Harrison, R. J. Turner. In Advances in Microbial Physiology, Vol. 53, pp. 1-72, Elsevier Academic Press, San Diego (2008).

98. Y. Ogra, R. Kobayashi, K. Ishiwata, K. T. Suzuki. J. Anal. At. Spectrom. 22, 153 (2007).

99. S. L. Braheny, P. W. Lampert. In Experimental and Clinical Neurotoxicology, P. S. Spencer, H. H. Schaumberg (Eds.), Williams and Wilkins, Baltimore (1980).

100. Y. Ogra, R. Kobayashi, K. Ishiwata, K. T. Suzuki. J. Inorg. Biochem. 102, 1507 (2008).

101. A. Taylor. Biol. Trace Elem. Res. 55, 231 (1996).

102. M. Filella, N. Belzile, M. C. Lett. Earth-Sci. Rev. 80, 195 (2007).

103. R. Bailly, R. Lauwerys, J. P. Buchet, P. Mahieu, J. Konings. Br. J. Ind. Med. 48, 93 (1991).

104. P. Andrewes, K. T. Kitchin, K. Wallace. Toxicol. Appl. Pharmacol. 194, 41 (2004).

105. J. Harrison, R. Leggett, D. Lloyd, A. Phipps, B. Scott. J. Radiol. Prot. 27, 17 (2007).

106. G. J. Hunt, H. S. Rumney. J. Radiol. Prot. 27, 405 (2007).

107. N. Momoshima, L. X. Song, S. Osaki, Y. Maeda. Environ. Sci. Technol. 35, 2956 (2001).

108. N. Hussain, T. G. Ferdelman, T. M. Church, G. W. Luther III. Aquat. Geochem. 1, 175 (1995).

109. N. Momoshima, L. X. Song, S. Osaki, Y. Maeda. J. Environ. Radioact. 63, 187 (2002).

110. N. Momoshima, A. Fukuda, A. Ishida, C. Yoshinaga. J. Radioanal. Nucl. Chem. 272, 413 (2007).

111. K. Michalke, J. Meyer, A. V. Hirner, R. Hensel. Appl. Organomet. Chem. 16, 221 (2002).

112. H. A. El-Masri, E. M. Kenyon. J. Pharmacokinet. Pharmacodyn. 35, 31 (2008).

113. E. M. Kenyon, M. F. Hughes, B. M. Adair, J. H. Highfill, E. A. Crecelius, H. J. Clewell, J. W. Yager. Toxicol. Appl. Pharmacol. 232, 448 (2008).

114. M. F. Hughes, V. Devesa, B. M. Adair, M. Styblo, E. M. Kenyon, D. J. Thomas. Toxicol. Appl. Pharmacol. 208, 186 (2005).

115. W. C. Hawkes, F. Z. Alkan, L. Oehler. J. Nutr. 133, 3434 (2003).

116. E. Dopp, L. M. Hartmann, A. M. Florea, A. W. Rettenmeier, A. V. Hirner. Crit. Rev. Toxicol. 34, 301 (2004).

117. J. M. Laparra, D. Velez, R. Barbera, R. Montoro, R. Farre. Toxicol. in Vitro 19, 1071 (2005).

118. J. M. Laparra, D. Velez, R. Barbera, R. Montoro, R. Farre. J. Agric. Food Chem. 55, 5892 (2007).

119. F. F. Farris, R. L. Dedrick, P. V. Allen, J. C. Smith. Toxicol. Appl. Pharmacol. 119, 74 (1993).

120. S. Possemiers, S. Rabot, J. C. Espin, A. Bruneau, C. Philippe, A. Gonzalez-Sarrias, A. Heyerick, F. A. Tomas-Barberan, D. De Keukeleire, W. Verstraete. J. Nutr. 138, 1310 (2008).

121. M. V. Ruby, A. Davis, R. Schoof, S. Eberle, C. M. Sellstone. Environ. Sci. Technol. 30, 422 (1996).

122. R. R. Rodriguez, N. T. Basta. Environ. Sci. Technol. 33, 642 (1999).

123. P. J. Turnbaugh, R. E. Ley, M. Hamady, C. M. Fraser-Liggett, R. Knight, J. I. Gordon. Nature 449, 804 (2007).

124. S. Bolca, S. Possemiers, A. Herregat, I. Huybrechts, A. Heyerick, S. De Vriese, M. Verbruggen, H. Depypere, D. De Keukeleire, M. Bracke, S. De Henauw, W. Verstraete, T. Van de Wiele. J. Nutr. 137, 2242 (2007). 
125. S. Bolca, S. Possemiers, V. Maervoet, I. Huybrechts, A. Heyerick, S. Vervarcke, H. Depypere, D. De Keukeleire, M. Bracke, S. De Henauw, W. Verstraete, T. Van de Wiele. Br. J. Nutr. 98, 950 (2007).

126. A. Hernandez, R. Marcos. Pharmacogenomics 9, 1113 (2008).

127. G. T. Macfarlane, H. N. Englyst. J. Appl. Bacteriol. 60, 195 (1986).

128. M. Minekus, P. Marteau, R. Havenaar, J. H. J. Huisintveld. Atla-Altern. Lab. Animals 23, 197 (1995).

129. T. Van de Wiele, N. Boon, S. Possemiers, H. Jacobs, W. Verstraete. FEMS Microbiol. Ecol. 51, 143 (2004).

130. B. Laube, S. Winkler, B. Ladstetter, T. Scheller, L. R. Schwarz. Arch. Toxicol. 74, 379 (2000).

131. K. A. Francesconi, F. Pannier. Clin. Chem. 50, 2240 (2004). 